ARCHIVO ESPAÑOL DE ARTE, LXXXVI, 342

ABRIL-JUNIO 2013, pp. 143-162

ISSN: 0004-0428

\title{
VARIA
}

\section{NUEVOS BUSTOS-RELICARIO FEMENINOS NAPOLITANOS DE HACIA 1630}

\author{
Carmen Fernández AhiJado \\ IES Leandro Fernández de Moratín
}

\begin{abstract}
Se estudian dos bustos-relicario femeninos de la colección del Instituto de Valencia de Don Juan y su relación con algunos de los conservados en Grajal de Campos. Su clasificación se determina por la conocida procedencia siciliana de los palentinos y su semejanza con otras series del tema estudiadas anteriormente y de procedencia italiana conocida del los siglos XVI y XVII.

Palabras clave: Escultura; Bustos-relicario femeninos; Siglo XVII; Instituto Valencia de Don Juan.
\end{abstract}

\section{NEW NEAPOLITAN FEMALE RELIQUARY-BUSTS OF CIRCA 1630}

Two female reliquary-busts in the collection of the Institute of Valencia de Don Juan and their relationship with those conserved in Grajal de Campos (Palencia) are the subject of this study. Their classification is based on the wellknown Sicilian origin of the Palencian pieces, as well as on their similarity to other previously-studied works of this type dating from the $16^{\text {th }}$ and $17^{\text {th }}$ centuries, and of known Italian origin.

Key words: Sculpture; female reliquary-busts; $17^{\text {th }}$ century; The Institute of Valencia de Don Juan.

Este breve trabajo se ocupa de dos piezas escultóricas de pequeño formato, unos $50 \mathrm{~cm}$ de altura, que pertenecen a la colección escultórica del Instituto de Valencia de Don Juan. El informe físico-químico facilitado por el Instituto de Patrimonio Histórico Español en el año 2003, al efectuar la restauración de dichas piezas, detectó oquedad en la parte anterior del pecho, lo que indicaba eran bustos-relicario de una época sin determinar y se reconvirtieron sencillamente en bustos femeninos, posiblemente por razones estéticas o comerciales.

Se trata pues de bustos-relicario femeninos interesantes desde el punto de vista artístico e iconográfico. Realizados en madera policromada, sus imágenes representan a dos santas sin atributos identificativos. La talla responde a unas características análogas, fundamentadas en la proporcionalidad de los rostros, la serenidad de expresión y la flexibilidad de los pliegues. Transmiten la idea de majestuosidad a través de su porte, definido por la elegancia en el vestir, La policromía es de carnaciones mates y la decoración de la indumentaria se reduce a un dorado y azulado en adornos.

Hay que recordar que aunque, al parecer, se ha respetado en lo posible la policromía primitiva, de hecho, al disimular el hueco de la teca es posible que hubiera retoques, así el elemento de la policromía no es fiable totalmente para determinar su clasificación. Su calidad escultórica, sin llegar a ser excepcional, denota; sin embargo una mano experta y una evidente filiación manierista en su ejecución. La ausencia de datos documentales concretos sobre estas obras impide confirmar 
si fueron traídas del extranjero o se encargaron a talleres locales, una vez que las reliquias estaban en suelo español. No obstante, los caracteres escultóricos que las definen apuntan a su posible procedencia italiana. No son de busto prolongado, a la manera que es de uso desde finales de la Edad Media y sobre todo en España durante el siglo XVII.

El primer busto, inventariado con el número 4.343, representa a una joven ricamente vestida. Tiene un complicado tocado que recubre los cabellos en la parte trasera, ciñéndolos mediante una diadema. Se viste con túnica sencilla de ribeteado escote cuadrado, con mangas fruncidas y manto abrochado en el hombro izquierdo. Lleva como adornos unos enormes pendientes de colgadura y un corto collar de granadura. La cabeza es de madera maciza, si bien el tronco está ahuecado. Presenta un expresivo rostro de grandes rasgos. De óvalo alargado, con mentón acentuado, posee una espaciosa frente, altas cejas, ojos con el iris coloreado, nariz recta y boca carnosa de labios ligeramente entreabiertos. El cabello está bosquejado y muy pegado al cráneo (fig. 1).

En el segundo busto, con número de inventario 4.344, destaca el aire clásico de la fisonomía: la amplia frente lisa, la nariz recta y vigorosa, el arqueamiento de las cejas, la formación carnosa y curvada de los labios, el modelado sintético de la cara, la solución ondulada y vermicular de los cabellos. Éste se ve reforzado por su indumentaria clásica, al modo de las doncellas romanas, la túnica de abundantes y finos pliegues, termina en corte recto y se ciñe al cuerpo por efecto de un arnés. El cabello partido deja caer un sinuoso mechón a cada lado hasta la altura de las orejas, desde donde queda cubierto por el velo del tocado que evoca los cascos guerreros. En actitud compungida, presenta rasgos fisonómicos de cierta frontalidad, acentuado este efecto por la caída recta del manto tras los hombros, siendo la torsión del cuello hacia el hombro izquierdo la que suaviza esta sensación (fig. 2).

En este tipo de obras sin referencias documentales el primer problema que se plantea es definir la posible escuela artística a la que pueden pertenecer. Por ello el primer paso de la investigación fue compararlas con los ejemplares flamencos y alemanes conocidos llegados unas fechas antes a España. Entre los que se recuerdan los cuatro bustos que llevó Francisco de los Cobos a su Sacra Capilla del Salvador en Úbeda, en donde en la actualidad sólo se conserva el que se identifica con Santa Aurelia. Otra serie de cinco, ahora depositada en el Museo de Bellas Artes de Vitoria, procedentes de la capilla que mandó construir en la iglesia de San Vicente de dicha ciudad Ortuño Ibáñez de Aguirre, consejero de Carlos I de España. Otros dos similares los de la catedral de Ávila, de los que Gómez Moreno recogió la siguiente inscripción: Esta virgen traxo de Alemania el dotor Luis Dávila et de Lobera, médico de la Magestae. A estos se pueden añadir los dos conservados en el Museo de los Caminos de Astorga, procedentes de la Colegiata de Villafranca. Los caracteres estilísticos diferentes a los que presentan los bustos en estudio descarta esta vía de investigación ${ }^{1}$.

Por ello se inició otro camino, pues en efecto a partir del Concilio de Trento esta corriente de importación de bustos-relicario cambia de sentido y se intensifica la que procede de Italia. Precisamente en la villa de Grajal de Campos (Palencia) se localizó una nueva serie de bustos-relicario, dos de ellos muy similares a los del Instituto de Valencia de Don Juan.

Se conoce la donación de reliquias que los señores de Grajal, Juan de Vega y Leonor de Osorio, virreyes de Sicilia, efectuaron en 1548 a la iglesia de su señorío. Puede aceptarse, como se dirá, que la mayoría de los relicarios que las contienen, en especial los más valiosos, procedan de Italia; aunque se sabe que algunos fueron realizados en España. Catorce de ellos se configuran en forma de busto-relicario, figurando entre los mismos seis santas, la mayoría sin atributos significativos; aunque algunas llevan inscripciones alusivas como Santa Teodora, Santa Bonese, Santa Rufina y Santa Domicela. Estas dos últimas por tamaño, fisonomía y actitudes son las más similares a las del Instituto de Valencia de Don Juan (figs. 3 y 4).

\footnotetext{
${ }^{1}$ Gómez Moreno, 1983: 105-10.
} 


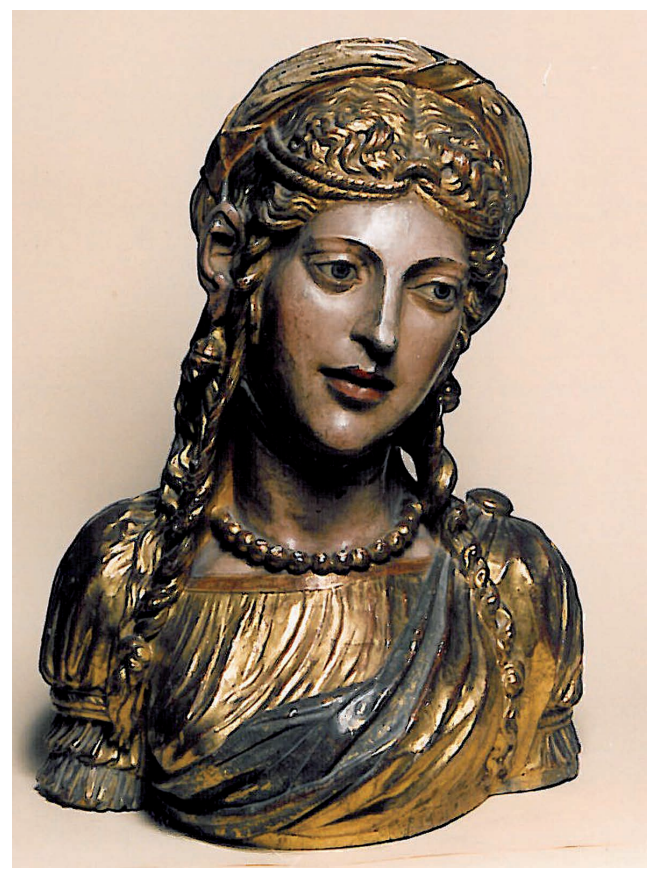

Fig. 1. Busto relicario-femenino. Instituto Valencia de Don Juan.

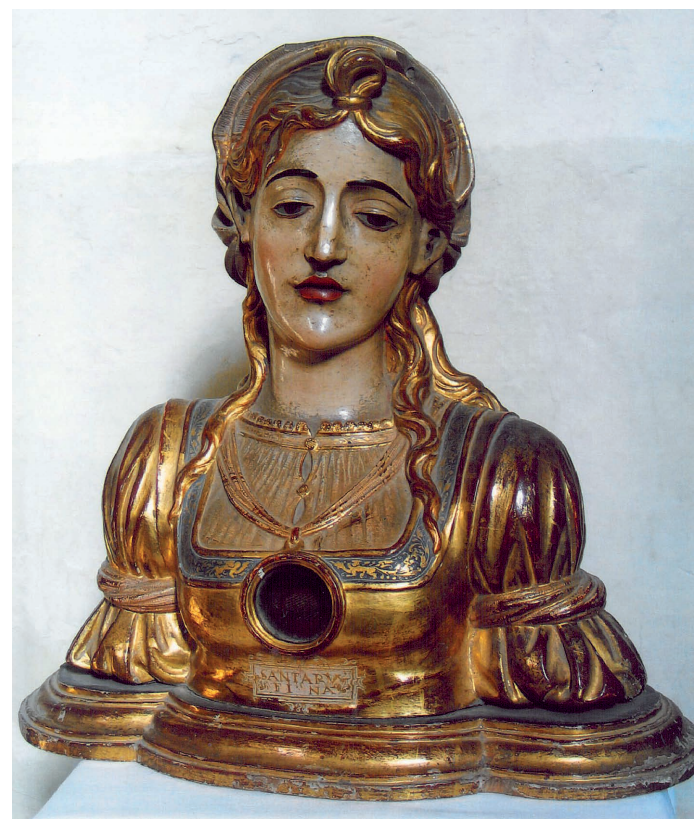

Fig. 3. Busto de Santa Bonese.

Iglesia de San Miguel. Grajal de Campos.

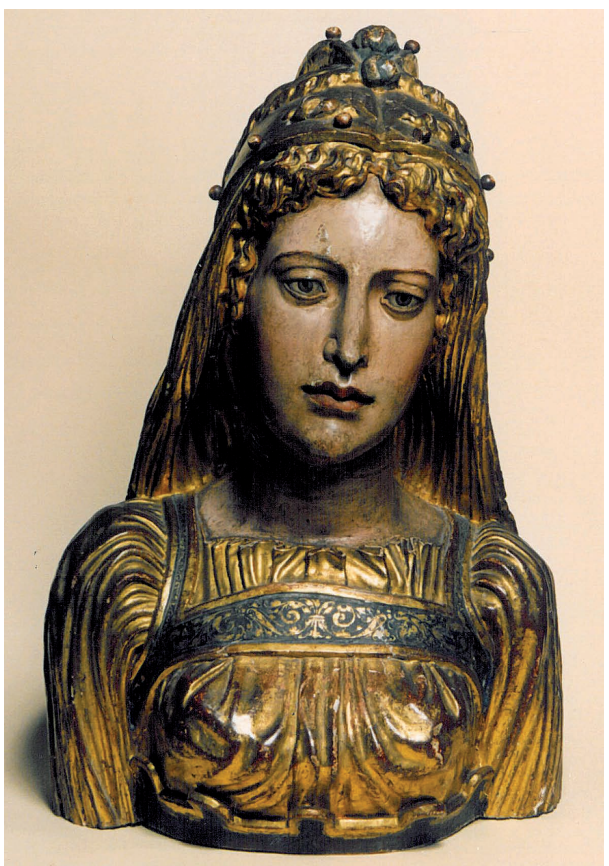

Fig. 2. Busto relicario-femenino. Instituto Valencia de Don Juan.

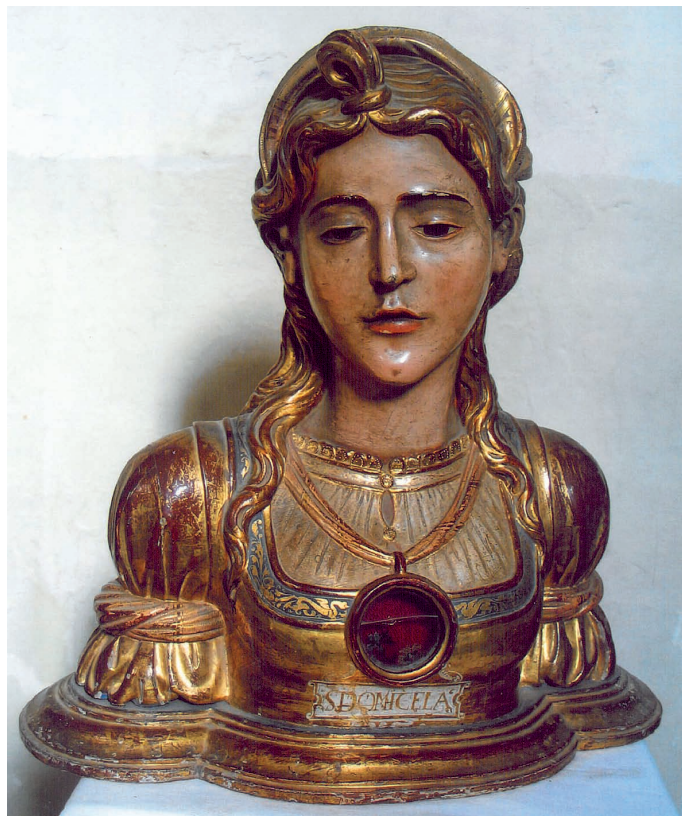

Fig. 4. Busto de Santa Domicela. Iglesia de San Miguel. Grajal de Campos.

Arch. esp. arte, LXXXVI, 342, ABRIL-JUNIO 2013, 143-162, ISSN: 0004-0428 
Son medios bustos - miden unos $45 \mathrm{~cm}$ de altura- y tienen la reliquia en un orificio abierto en el pecho, que está enmarcado por una moldura circular lisa. Se componen en actitudes reconcentradas y ofrecen una idealizada belleza de raíz clásica. Están enteramente policromados y visten con túnica de mangas abullonadas y escote bajo con gorguera abotonada al centro y rematada con fina lechuguilla, del cuello pende una ancha cinta que sostiene, a modo de medalla, la teca. El tratamiento del cabello es naturalista, dispuesto en largos mechones ondulados que enmarcan el rostro o caen sobre la espalda, mientras un sencillo paño fruncido cubre el centro del cráneo sirviendo de tocado ${ }^{2}$.

El testamento de $\mathrm{D}^{\mathrm{a}}$ Leonor de Osorio fechado en Palermo el 13 de febrero de 1550 afirma: “mando a mi hija $D^{a}$ Isabel seis imágenes de las que yo tengo cuales ella quisiere escoger", que lógicamente serían de factura italiana y que se destinarían a su iglesia de Grajal de Campos. No creemos sea arriesgado pensar que los seis bustos de santas conservados sean las seis imágenes enviadas desde Palermo.

Con el objeto de confirmar este origen italiano y la cronología de las piezas de Grajal y en consecuencia, por su parecido, de las conservadas en el Instituto de Valencia de Don Juan; se revisaron las noticias sobre otros conjuntos similares de origen italiano y cronología conocida documentados. En síntesis se recuerdan los bustos-relicario de Santa Clara de Medina de Pomar, procedentes del legado artístico de Juan Fernández de Velasco y familiares, XI Condestable de Castilla, que deposita en dicho monasterio en 1610 el conjunto de reliquias y relicarios que habían atesorado varios miembros de su familia, entre los que figuran seis bustos policromados de santas ricamente vestidas. En el cuello de la camisa de una de ellas se lee: S. JULIANA sobre la que su correspondiente certificación aclara que la "de santa Juliana virgen y martyr contenida en un testimonio del obispo de Como que se la dio a mi señora la duquesa de Frias doña María de Girón, que está en el cielo, con otras reliquias" en mayo de 1598. Es probable que el obispo le regalara el conjunto de las seis, para las que se harían los relicarios pues en 1608 había en el oratorio de la duquesa "seis caveças de virgenes con reliquias" que han de corresponder con las conservadas de estilo romanista ${ }^{3}$ (fig. 5).

Los relicarios se harían en Italia entre enero de 1607, cuando enviaron las últimas reliquias incorporadas, y mayo de 1610, fecha de la donación. Pues según Barrón García se pueden vincular al taller de los Saracchi, artífices con los que el Condestable se relacionó para satisfacer encargos reales. La mención del donante de la reliquia de Santa Juliana parece decidió al autor a clasificar su busto como obra de taller lombarda. Los dos relicarios principales los hubo de encargar después de la muerte de su primogénito ocurrida en 1607, cuando decidió engrandecer el panteón medinés. Otra serie de bustos-relicario es la que decora el retablo de la Capilla de los Barrionuevo, en la iglesia de San Ginés de Madrid, que proceden muy posiblemente de Nápoles, pues se mencionan en relación a la escultura en bronce del Licenciado García de Barrionuevo encargada en aquellas ciudad el año de 1607 al Nacherino por el Marqués de Cusano, Bernardino García de Barrionuevo, hijo del Licenciado fundador de la capilla madrileña ${ }^{4}$. La serie responde a los caracteres de la que aparece en uno de los relicarios de la capilla de Santa Ana en la iglesia del Gesù Nuovo de Nápoles, algunos de los cuales eran posible obra de Giovanni Battista Gallone. Autoría defendida por el profesor Leone de Castris en base a un documento de 1617, por el cual se conoce que en dicha fecha el artista realizaba cuarenta bustos-relicario para el padre Pietro Provedi de la Compañía de Jesús de Nápoles ${ }^{5}$ (fig. 6).

\footnotetext{
2 Campos Sánchez-Bordona, 1995: 33-65.

${ }^{3}$ Barrón García, 2004: 207-276.

${ }^{4}$ Estella Marcos, 2005: 331-345.

5 Leone de Castris, 2007: 5-36.
} 
Como se sabe que el Nacherino también trabaja por esos años en esta iglesia, el hecho pudo influir en la selección del anterior artista para la realización de los bustos de San Ginés.

Manuela Sáez mantiene que, según la documentación hallada en el convento de las Madres Clarisas de Monforte de Lemos, a partir de 1613 se encargan a los artistas que trabajan en Nápoles, a Pietro Quatraro y Giovan Battista Ortega, la ejecución de seis bustos de vírgenes y mártires, que entregarían los días 24 de cada mes. Considera que entre los ejemplares ejecutados por estos dos artistas se hallan los de Santa Lucía y Santa Catalina de Alejandría, que adoptan el esquema de esculturas romanas y llevan atributos simbólicos de su identificación ${ }^{6}$ (fig. 7).

En las series señaladas se aprecia la evolución iconográfica del busto-relicario femenino. Mientras los de finales del siglo XV y principios del XVI presentan una estética goticista manifestada en la frontalidad de las figuras, en la riqueza de su indumentaria y en la

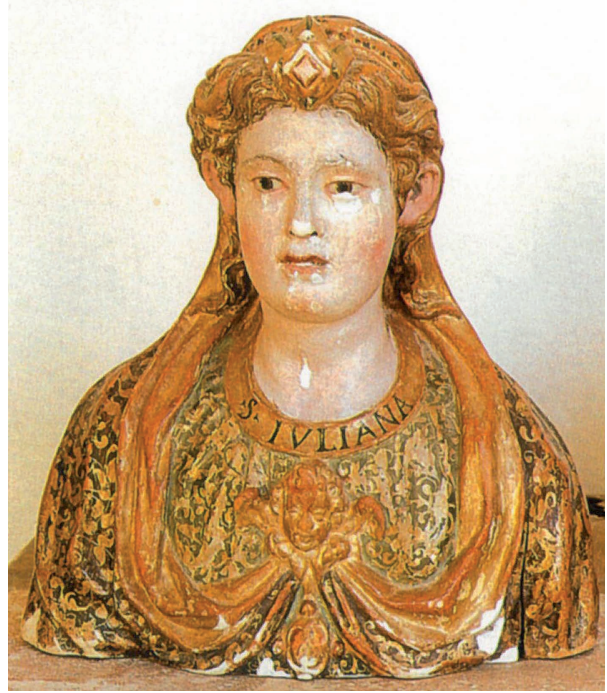

Fig. 5. Busto de Santa Juliana. Monasterio de Santa Clara. Medina de Pomar. inocencia de sus rostros; los que corresponden a mediados de la centuria, aún manteniendo la actitud de recogimiento, muestran una torsión de sus cuellos que proporciona mayor naturalismo, a lo que también contribuye la sencillez de sus ropajes y tocados. Ya a finales de siglo la desacralización es más notoria, presentando peinados, túnicas y adornos

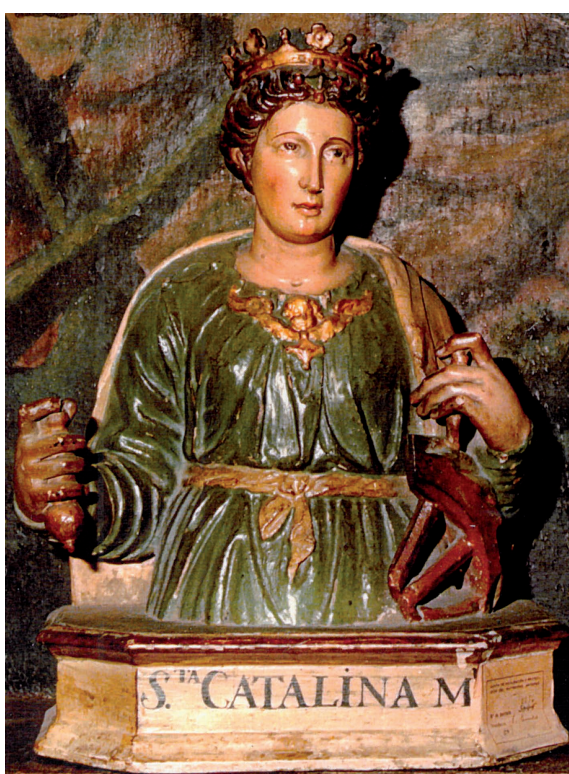

Fig. 6. Busto de Santa Catalina. Iglesia de San Ginés. Madrid. propios de damas cortesanas. Al entrar en la centuria siguiente se acentúa el realismo mediante una mayor altura de los bustos, el movimiento de los brazos que sostienen símbolos del martirio, la expresividad de los rostros y la moda a la romana.

La breve revisión de estas series manifiestan caracteres comunes a los que aparecen en los bustos del Instituto de Valencia de Don Juan y en los que Grajal de Campos, como la dulzura de sus facciones diluida en el aire de concentración en sí mismas, la elegancia de sus túnicas y tocados y la misma o muy similar estructura del busto. Ello no es de extrañar pues como aclara Pierluigi Leone de Castris la fortuna comercial de estatuas y especialmente de bustos-relicario en madera italianos, particularmente napolitanos, atestiguada en los documentos a partir del último decenio del Cinquecento y luego, de modo más intenso, en los dos primeros decenios del Seiscento, fomentó su proliferación y difusión por Europa. El autor recuerda a algunos de sus artífices como Nuncio, Giovanni Lorenzo Maresco, Pietro Quatraro, Giovan Battista Ortega y Giovan Bat-

\footnotetext{
${ }^{6}$ SÁez GonZÁlez, 2006: 51-74.
} 


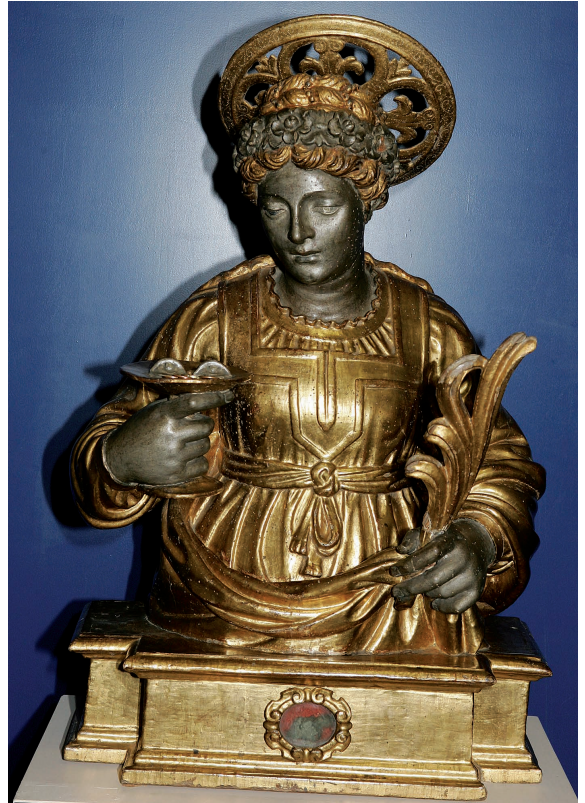

Fig. 7. Busto de Santa Lucía. Convento Madres Clarisas. Monforte de Lemos.

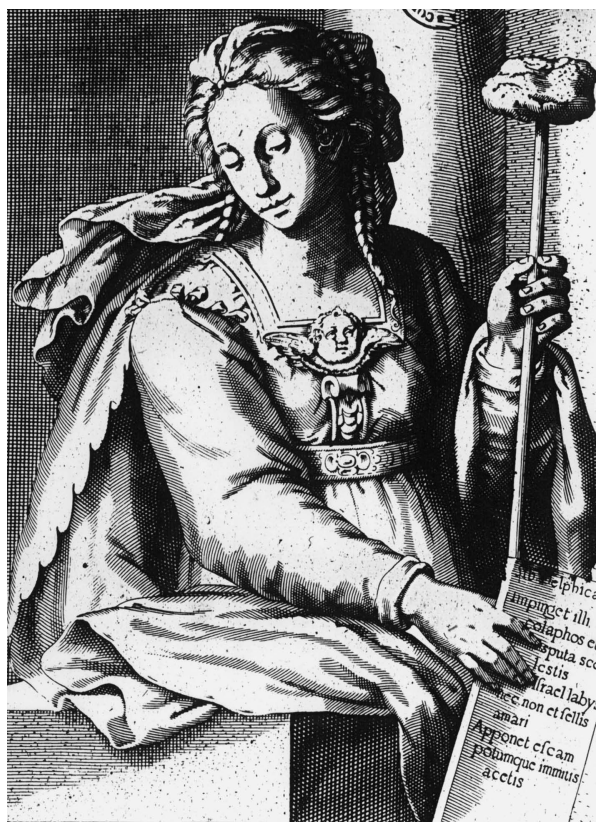

Fig. 8. Sibila Delphica. Grabador Huys (1522-1562).

tista Gallone que son comisionados por las Órdenes, las iglesias y los particulares para la elaboración de contenedores antropomorfos de reliquias. El mundo visual del manierismo italiano se difunde en todos los talleres bien directamente o más frecuentemente a través de grabados como las sibilas Delphica y Cumea realizadas por el grabador Huys (1522-1562). Las composiciones de los (fig. 8) más variados artistas proporcionan los elementos utilizados por artífices menores en sus obras.

Vistos los antecedentes nos atrevemos a clasificar las obras del Instituto de Valencia de Don Juan y las de Grajal de Campos, sin duda muy similares entre sí, como sicilianas de fines del siglo XVI, dado el dato que muestra la posible relación de la familia Vega con Sicilia, que probablemente aún se mantuvo en fechas posteriores. En realidad pueden considerarse en la órbita de la escuela napolitana de la época, que incluye la de Sicilia, en concreto en el campo de los bustos-relicario, magistralmente estudiados recientemente por Pierluigi Leone de Castris ${ }^{7}$. Entre todos los nombres es difícil encuadrarlas en la actividad de un artista concreto, sin datos documentales en que apoyarse. Lo único factible es la comparación estilística entre los ya estudiados por el citado profesor y las coincidencias que aparecen con los aquí dados a conocer. Mayor similitud vemos, como se ha dicho, entre los del Instituto de Valencia de Don Juan y los de Grajal de Campos y entre los del monasterio de Medina de Pomar y algunos de Monforte de Lemos. Indudablemente los del Instituto de Valencia de Don Juan pueden asimilarse artísticamente con los de Grajal de Campos porque coinciden en muchos de sus caracteres y ambos pueden relacionarse con esa producción de la que se ha hablado.

\footnotetext{
${ }^{7}$ LeONE DE CASTRIS, 2008: 19-47.
} 


\section{BIBLIOGRAFÍA}

Barrón García, Amparo.: "Patrimonio artístico y monumental. El legado de Juan

Fernández de Velasco y familiares", en El monasterio de Santa Clara en Medina de Pomar. Fundación y Patrimonio de la Casa de Velasco. Burgos, 2004, pp. 207-276.

Campos Sánchez-Bordona, Ma Dolores. Arquitectura y Mecenazgo de la Casa de Grajal de Campos. León, 1995, pp. 33-65.

Estella Marcos, Margarita.: "La escultura napolitana en España: la importancia de las esculturas a través del mecenazgo virreinal y personajes de su entorno", en El arte foráneo en España: presencia e influencia de los artistas foráneos. Jornadas de Arte. C.S.I.C. Madrid, 2005, pp. 331-345.

Gómez Moreno, Manuel. Catálogo Monumental de Ávila, 1983.

Leone de Castris, Pierluigi. "Nomi e date per la scultura in legno di primo seicento fra Napoli e le province: dai busto del Gesú a quelli di Tricarico", en La scultura meridionale in età moderna nei suoi rapporti con la circolazione mediterranea. Atti del Convengo Internazionale di Studi. Salento, 2007, pp. 5-36.

Leone de Castris, Pierluigi. "Sculture in legno di primo Seicento in Terra d Otranto, tra produzione locale e importazioni da Napoli”. Sculture di età baroca tra Terra d Otranto, Napoli e la Sapgna. Napoli, 2008, pp. 19-47.

Sáez González, Manuela.: "Escultores, entalladores y marmolistas que trabajaron en Nápoles para el virrey Lemos (1610-1616)” en Ricerche sul 600 napoletano, Nápoles 2006. pp. 51-74.

Fecha de recepción: 3-VIII-2012

Fecha de aceptación: 13-III-2013

Arch. esp. arte, LXXXVI, 342, ABRIL-JUNIO 2013, 143-162, ISSN: 0004-0428 